\title{
オートクレーブ養生コンクリートおよびこれに ポリマーを含浸したコンクリートの耐楽品性*
}

福 地 利 $*^{* *}$ 大浜 嘉 彦**

\author{
Chemical Resistance of Autoclaved Concrete with and \\ without Polymer Impregnation
}

by

\section{Toshio FukUchI and Yoshihiko OHama}

(College of Engineering, Nihon University, Koriyama)

Cement concrete is a most popular structural material at present, but its basic weakness is a limited chemical resistance to various chemical agents.

In this paper, autoclaved concrete (AC), polystyrene-impregnated autoclaved concrete (PIAC) and water-cured concrete (WCC) were prepared and tested for chemical resistance to ten types of chemical agents such as hydrochloric acid, sulfuric acid, sodium hydroxide, etc. .

The conclusions obtained are summarized as follows:

(1) In general, the chemical resistance of various concretes is in the following order; (good) PIAC $>$ AC $>$ WCC (bad).

(2) The aggressive chemical agents that attack markedly various concretes are hydrochloric acid, sulfuric acid, ammonium sulfate, etc. .

(3) It seems that the chemical resistance of various concretes depends on the formation of free $\mathrm{Ca}(\mathrm{OH})_{2}$ (highly reactive and susceptible to attack by chemical agents) and tobermorite (chemically resistant and watertight, produced as a result of autoclaving) in them.

(4) The superior chemical resistance of PIAC is due to the impregnation of autoclaved concrete with chemically resistant polymer (polystyrene).

(Received Mar. 22, 1977)

\section{1 緒言}

現在, 土木・建築分野に和いて, 最も一般的な構造 材料の一つであるセメントコンクリートは, 化学組成 飞拈汸る本質的な面から, 種及の化学薬品に対する抵 抗性に乏しい, そのため, 製紙, めっき, 発酵, 塗料, 電解, 肥料などの化学工業や機械工業の工場床, 壁, 廃液こうなどに使用されているコンクリートは浸食さ れやすく，しばしば大きな被害を生じている。

ところで，セメントに適当量のシリカを加光て作っ たコンクリートをオートクレーブ養生すると, その硬 化体は, 高強度の短期発現, 乾燥収縮の低減, 而衝撃 性・耐薬品性にすぐれるなど，多くの特長を持つこと が知られている、オートクレーブ養生に淤汗るこれら の特長は, 水熱合成による硬化体 (11 $\AA$ tobermorite など）の組織構造に由来するといわれる。そして,オ

* 原稿受理 昭和52年 3 月22日

** 正会員 郡山市田村町 日本大学工学部
ートクレーブ養生コンクリートのこれらの特長のらち, とくにその耐薬品性については, 従来, 文献上から優 秀であるとの記述はあるが，具体的にその事象を明ら かにした研究報告は活としどなく、杉木らの行った $5 \%$ 塩酸拈よび硫酸に対する実験例があるのみである。 しかしながら，オートクレーブ養生コンクリート製品 の実際の使用にあたっては, 設計上から, 薬品の種類 や濃度などがそれに及ぽす影響を具体的に知る必要が 西る.

そこで, 本研究ではオートクレーブ養生コンクリー 卜の耐薬品性を検討するため, 塩酸, 硫酸, 水酸化ナ トリウムなど10種類の薬品について浸せき実験を行い， その結果を標準養生の普通コンクリート㧧よびポリマ 一を含浸したオートクレーブ養生コンクリートの場合 と比較した.

\section{2 使 用 材 料}

コンクリート用材料は, 普通ポルトランドセメント, 
Table I. Chemical compositions and physical properties of cement.

\begin{tabular}{|c|c|c|c|c|c|c|c|c|c|c|}
\hline \multicolumn{11}{|c|}{ Chemical compositions (\%) } \\
\hline Ig. loss & \multicolumn{2}{|l|}{ Insol. } & $\mathrm{S}_{1} \mathrm{O}_{2}$ & $\mathrm{Al}_{2} \mathrm{O}_{3}$ & $\mathrm{Fe}_{2} \mathrm{O}_{3}$ & $\mathrm{CaO}$ & $\mathrm{MgO}$ & \multicolumn{2}{|c|}{$\mathrm{SO}_{3}$} & Total \\
\hline 0.6 & \multicolumn{2}{|l|}{0.0} & 22.3 & 4.9 & 3.2 & 652 & 1.0 & \multicolumn{2}{|c|}{22} & 994 \\
\hline \multicolumn{11}{|c|}{ Physical properties } \\
\hline Specific & \multicolumn{2}{|c|}{ Fineness } & \multicolumn{2}{|c|}{ Setting time } & \multirow{2}{*}{\multicolumn{3}{|c|}{$\begin{array}{l}\text { Bending strength } \\
\left(\mathrm{kg} / \mathrm{cm}^{2}\right)\end{array}$}} & \multirow{2}{*}{\multicolumn{3}{|c|}{$\begin{array}{c}\text { Compressive strength } \\
\qquad\left(\mathrm{kg} / \mathrm{cm}^{2}\right)\end{array}$}} \\
\hline gravity & \multirow{2}{*}{\begin{tabular}{|} 
Residue on \\
sieve of $88 \mu$ \\
$(\%)$
\end{tabular} \mid} & \multirow{2}{*}{$\begin{array}{l}\text { Blaine's } \\
\text { specific } \\
\text { surface } \\
\text { area } \\
\left(\mathrm{cm}^{2} / \mathrm{g}\right)\end{array}$} & \multirow{2}{*}{$\begin{array}{l}\text { Initial set } \\
(\mathrm{h}-\mathrm{min})\end{array}$} & \multirow{2}{*}{$\begin{array}{l}\text { Final set } \\
\text { (h-min) }\end{array}$} & & & & & & \\
\hline$\left(20^{\circ} \mathrm{C}\right)$ & & & & & 3 days & 7 days & 28 days & 3 days & 7 days & 28 days \\
\hline 3.16 & 1.4 & 3170 & $1-58$ & $3-30$ & 36.9 & 553 & 764 & 153 & 241 & 404 \\
\hline
\end{tabular}

Table II. Properties of aggregates.

\begin{tabular}{l|c|c|c|c}
\hline $\begin{array}{l}\text { Type of } \\
\text { aggregate }\end{array}$ & $\begin{array}{c}\text { Size } \\
(\mathrm{mm})\end{array}$ & $\begin{array}{c}\text { Spec1fic } \\
\text { gravity } \\
\left(20^{\circ} \mathrm{C}\right)\end{array}$ & $\begin{array}{c}\text { Water } \\
\text { absorption } \\
(\%)\end{array}$ & $\begin{array}{l}\text { Organic } \\
\text { 1mpurities }\end{array}$ \\
\hline $\begin{array}{l}\text { Kinugawa } \\
\text { river sand }\end{array}$ & $<2.5$ & 2.60 & 1.68 & No \\
$\begin{array}{l}\text { Kinugawa } \\
\text { river grave1 }\end{array}$ & $5-20$ & 2.60 & 191 & No \\
$\begin{array}{l}\text { Crushed } \\
\text { andesite }\end{array}$ & $<20$ & 259 & 3.01 & No \\
\hline
\end{tabular}

Table III. Properties of silica.

\begin{tabular}{|c|c|c|c|c|}
\hline \multirow{2}{*}{$\begin{array}{l}\text { Specific } \\
\text { gravity } \\
\left(20^{\circ} \mathrm{C}\right)\end{array}$} & \multirow{2}{*}{$\begin{array}{c}\text { Fineness } \\
\begin{array}{c}\text { Residue on } \\
\text { sieve of } 44 \mu \\
(\%)\end{array}\end{array}$} & \multicolumn{3}{|c|}{ Chemical compositions (\%) } \\
\hline & & $\mathrm{SiO}_{2}$ & $\mathrm{Al}_{2} \mathrm{O}_{3}$ & $\mathrm{Fe}_{2} \mathrm{O}_{3}$ \\
\hline 2.63 & 100 & 9970 & 0.15 & 0.15 \\
\hline
\end{tabular}

Table IV. Properties of styrene monomer.

\begin{tabular}{l|c|c|c|c}
\hline $\begin{array}{l}\text { Molecular } \\
\text { weight }\end{array}$ & $\begin{array}{c}\text { Specific } \\
\text { gravity } \\
\left(20^{\circ} \mathrm{C}\right)\end{array}$ & $\begin{array}{c}\text { Boiling } \\
\text { point } \\
\left({ }^{\circ} \mathrm{C}\right)\end{array}$ & $\begin{array}{c}\text { Flash } \\
\text { point } \\
\left({ }^{\circ} \mathrm{C}\right)\end{array}$ & $\begin{array}{c}\text { Surface } \\
\text { tension } \\
\left(20^{\circ} \mathrm{C}, \text { dyne/cm }\right)\end{array}$ \\
\hline 104.14 & 0.902 & 1452 & 31.0 & 31.7 \\
\hline
\end{tabular}

鬼怒川産川砂（以上各種コンクリートとも共通），鬼 怒川産川砂利 (WCC および AC 用), 初狩産安山岩 砕石 (PIAC 専用) 招よび高純度シリカ（AC 拈よび PIAC 用) であり，それらの性質を示すと, Table I 〜III のと㧊りである.

含浸材は工業用スチレンモノマー, 架橋剤としてト リメチロールプロパントリメタクリレート，重合触蝶 として2，2'-アゾビスイソブチロニトリル，カップリ ング剤として シシランから成り, このうち, スチレンモノマーの性 質を示すと, Table IV のと拈りである.

供試薬液は各種の薬品グループの中で代表的なるの， 化学的浸食が工業的に問題になっているものから10種 選んだ.すなわち, 塩酸, 硫酸, 酩酸, 水酸化ナトリ ウム, 硫酸アンモニウム, 塩化ナトリウム(以上いずれ も試薬一級品), ナタネ油, 重油, 登油, 生ビールである.

\section{$3 \cdot 1$ 供試体の種類 (記号) \\ 3 実 験 方 法}

実験は次の 3 種の供試体について行った。

（1）標準養生コンクリート（略称，WCC)

（2）オートクレーブ養生コンクリート（略称， AC）

（3）ポリマー含浸オートクレーブニンクリート（略 称, PIAC)

\section{$3 \cdot 2$ 供試体の作製}

$3 \cdot 2 \cdot 1$ WCC 供試体 Table V 亿示す調合の二 ンクリートをJIS A 1132 (コンクリートの強度試験用 供試体の作り方）に準じて, 寸法 $\phi 7.5 \times 15 \mathrm{~cm}$ の供 試体に成形し, 24 時間, $20^{\circ} \mathrm{C}, 80 \%$ R.H. の湿空養生 を行って, 脱型後, 27 日間, $20^{\circ} \mathrm{C}$ 水中養生を行った. な掠，実験の性質上キャッピングは行わないこととし た. 以下， AC および PIAC についても同様である.

$3 \cdot 2 \cdot 2 \mathrm{AC}$ 供試体 Table V K示言調合のコン クリートをWCC と同様, JIS A 1132 そ準じて, 寸 法 $\phi 7.5 \times 15 \mathrm{~cm}$ の供試体に成形し, $20^{\circ} \mathrm{C}, 80 \%$ R. H. の恒温恒湿室にて24時間前養生し, 脱型後, 直ちにオ ートクレーブ養生を行った.オートクレーブの養生条 件は, Fig. 1 飞示すと招りである.

$3 \cdot 2 \cdot 3$ PIAC 供試体 Table $\mathrm{V}$ 亿示す調合のコ ンクリートを, ACC と全く同様な手順でオートクレ ーブ養生を行い，さらに Fig. 2 に示すプロセスでポり マーを含浸せしぬた．このようにして得られる PIAC のポリマー含浸率は, 次式のごとく計算され,

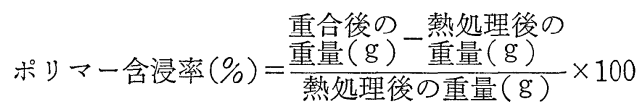

本実験では 5.5 6.5\% (重量)の範囲にあった.

なお，各種コンクリートの清水によって求めた拈よ その気孔率は, WCC では 0.105, AC では 0.014, PIAC では 0.003 である.

\section{$3 \cdot 3$ 薬液の種類および調製}

$3 \cdot 3 \cdot 1$ 種類 供試薬液は, 各種の薬品グループ 
Table V. Mix proportions of concrete.

\begin{tabular}{|c|c|c|c|c|c|c|c|c|c|}
\hline \multirow{2}{*}{ Type of concrete } & \multirow{2}{*}{$\begin{array}{l}\text { Water- } \\
\text { cement } \\
\text { ratio } \\
W / C(\%)\end{array}$} & \multirow{2}{*}{$\begin{array}{l}\text { Slump } \\
(\mathrm{cm})\end{array}$} & \multirow{2}{*}{$\begin{array}{l}\text { Water content } \\
\text { per unit volume } \\
\text { of concrete } \\
\qquad\left(\mathrm{kg} / \mathrm{m}^{3}\right)\end{array}$} & \multicolumn{5}{|c|}{ Mix proportions by weight $\left(\mathrm{kg} / \mathrm{m}^{3}\right)$} & \multirow{2}{*}{$\begin{array}{l}\text { Air } \\
\text { content } \\
\text { (\%) }\end{array}$} \\
\hline & & & & Cement & Silica & $\begin{array}{l}\text { River } \\
\text { sand }\end{array}$ & $\begin{array}{l}\text { River } \\
\text { gravel }\end{array}$ & $\begin{array}{l}\text { Crushed } \\
\text { andesite }\end{array}$ & \\
\hline Concrete for water curing & 50.0 & 11.0 & 175 & 350 & - & 809 & 1023 & - & 1.5 \\
\hline Concrete for autoclaving & 50.0 & 12.4 & 174 & 208 & 139 & 800 & 1014 & - & 1.3 \\
\hline $\begin{array}{l}\text { Concrete for polymer- } \\
\text { impregnation after autoclaving }\end{array}$ & 50.0 & 11.7 & 194 & 233 & 155 & 710 & - & 1065 & 2.0 \\
\hline
\end{tabular}

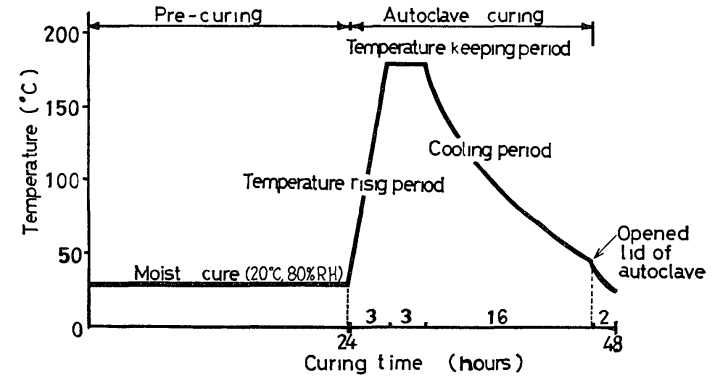

Fig. 1. Diagram for pre-curing and autoclaving.
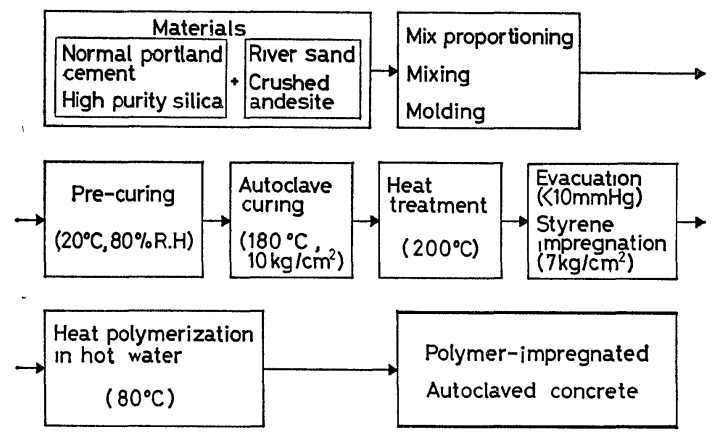

Fig. 2. Preparation process of polymer-impregnated autoclaved concrete specimens.

の中で代表的なもの和よび化学的浸食が工業的に問題 になっているものの中から，10種選択した．以下にそ の分類を示す。

(1) 酸 類

(a) 無機酸: $5 \%$ 塩酸 $(\mathrm{HCl}), 5 \%$ 硫酸 $\left(\mathrm{H}_{2} \mathrm{SO}_{4}\right)$

(b) 有機酸: $5 \%$ 酢酸 $\left(\mathrm{CH}_{3} \mathrm{COOH}\right)$

（2）アルカリ類： $50 \%$ 水酸化ナトリウム $(\mathrm{NaOH})$

(3) 塩類（主に無機塩類）

（a）硫酸塩：43\%（飽和）硫酸アンモニウム

$$
\left[\left(\mathrm{NH}_{4}\right)_{2} \mathrm{SO}_{4}\right]
$$

（b）塩化物：26.5\%(飽和)塩化ナトリウム $(\mathrm{NaCl})$

(4) 油 類

(a) 植物油：ナタネ油

(b) 鉱物油: A 重油, 登油

(5) その他：生ビール

$3 \cdot 3 \cdot 2$ 調製 薬液の調製にあたって, 無機酸, 有機酸, アルカリ, 塩類など水溶性の薬品は, 試薬一 級, あるいは工業用のものを水で一定濃度に溶解・希
釈し，油類など，水に不溶性なものは，そのまま使用 した.

\section{$3 \cdot 4$ 耐薬品性試験方法}

而薬品性試験は ASTM C 267-65 (Standard Method of Test for Chemical Resistance of Mortars) に準じて行った. WCC 供試体は27日間水中養生後, 表面水を拭い，直ちに所定の薬液中に 浸せきした。 $\mathrm{AC}$ 抒よび PIAC 供試体㹥所定の養生招よび処理を行 った後, 48時間水中につけたるのを所定の薬液中に浸 せきしたなな拈，試験方法は，A打よびB法の二種と した、A法は浸食部分をはぎ取らないもの，B法は一 定期間ごとに浸食部分をはぎ取る方法をいら。

供試薬液の濃度, 薬液交換サイクルは Table VIに 示すと招りである．な拈，薬液は試験期間中，恒温恒 湿室にて $20^{\circ} \mathrm{C}, 80 \%$ R. H を保った.

Table VI. Testing procedures.

\begin{tabular}{l|c|l}
\hline \multicolumn{1}{c|}{ Reagents } & Testing methods & $\begin{array}{l}\text { Changing of } \\
\text { 1mmersion medium }\end{array}$ \\
\hline $5 \% \mathrm{HCl}$ & A, B & Every 3 days \\
$5 \% \mathrm{H}_{2} \mathrm{SO}_{4}$ & A, B & Every 3 days \\
$5 \% \mathrm{CH}_{3} \mathrm{COOH}$ & A, B & Every 3 days \\
$50 \% \mathrm{NaOH}$ & A & No change \\
$43 \%$ (Sat.) $\left(\mathrm{NH}_{4}\right)_{2} \mathrm{SO}_{4}$ & A & Every 3 days \\
$26.5 \%$ (Sat.) $\mathrm{NaCl}_{\text {Rapeseed oil }}$ & A & No change \\
Heavy oil (A-grade) & A & Every 7 days \\
Kerosene & A & No change \\
Draught beer & A & No change \\
\hline
\end{tabular}

Method A …... No cleaning of the attacked portion of specimen Method B...... Cleaning of the attacked portion of specimen after 3,7 and 28 days of immersion

重量測定は，浸せき前，3日，7日，28日の 4 回と し，重量変化率は次式を用いて計算した。

$$
\text { 重量変化率 }(\%)=\frac{\frac{\text { 浸せき後の一浸せき量 }(\mathrm{g}) \text { 前の }}{\text { 浸せき量 }(\mathrm{g})}}{\text { 前の重量 }(\mathrm{g})} \times 100
$$

ただし，重量変化率の正数值は重量増加を，負数值は 重量減少を表するのとする.

\section{4 試 験 結 果}

試験結果は Fig. 3〜10 に示すとおりである.

$$
5 \text { 考察 }
$$




\section{$5 \cdot 1$ 酸類に対する抵抗性}

試験方法 A和よびB法にかかわらず, 塩酸, 硫酸 および酢酸の各 $5 \%$ 溶液に対してはいずれの場合も, 浸せき期間が増加するにつれて，AC， PIAC および WCC の重量は急激に減少する傾向にあり, その外観

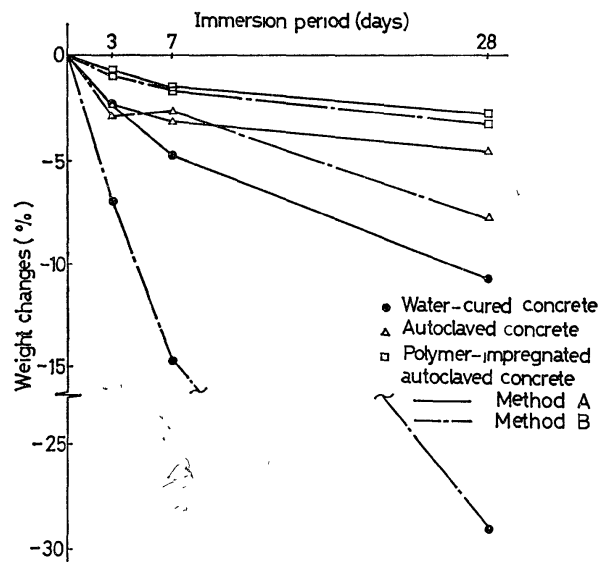

Fig. 3. Immersion period vs. weight changes of specimens immersed in $5 \% \mathrm{HCl}$ (Method $A$ and $B)$.

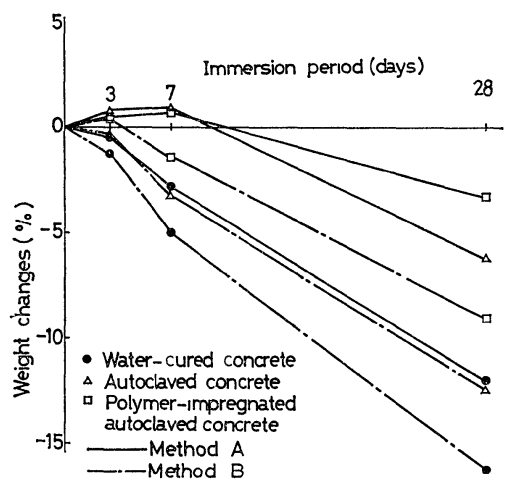

Fig. 4. Immersion period vs. weight changes of specimens immersed in $5 \% \mathrm{H}_{2} \mathrm{SO}_{4}$ (Method $\mathrm{A}$ and $\mathrm{B}$ ).

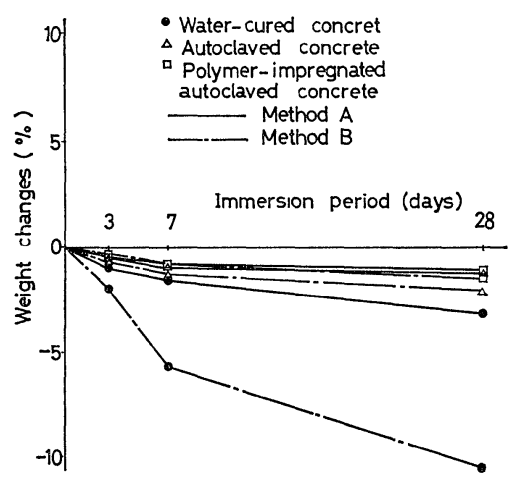

Fig. 5. Immersion period vs. weight changes of specimens immersed in $5 \% \mathrm{CH}_{3} \mathrm{COOH}$ (Method $\mathrm{A}$ and $\mathrm{B}$ ).

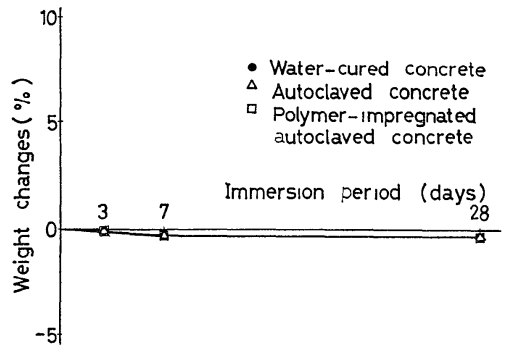

Fig. 6. Immersion period vs. weight changes of specimens immersed in $50 \% \mathrm{NaOH}$ (Method A).

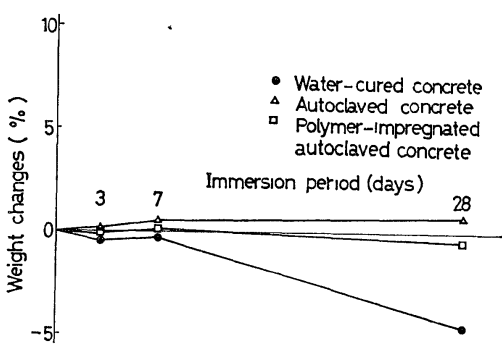

Fig. 7. Immersion period vs. weight changes of specimens immersed in $43 \%$ (Sat.) $\left(\mathrm{NH}_{4}\right)_{2} \mathrm{SO}_{4}$ (Method A).

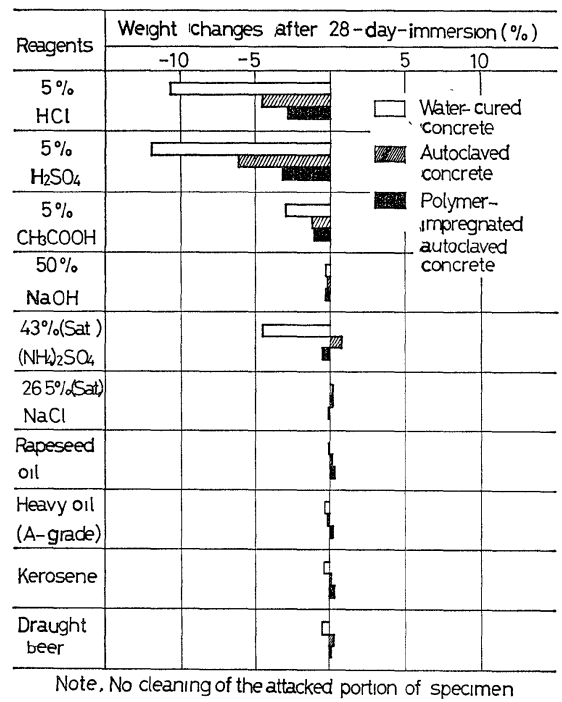

Fig. 8. Weight changes of specimens after 28-dayimmersion in various reagents (Method A).

\begin{tabular}{|c|c|c|c|}
\hline \multirow{2}{*}{ Reagents } & \multicolumn{3}{|c|}{ Weight changes after 28 -day-immersion ( $\%$ ) } \\
\hline & -20 & -10 & 20 \\
\hline $\begin{array}{l}5 \% \\
\mathrm{HCl}\end{array}$ & & 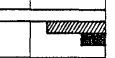 & 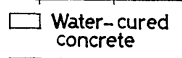 \\
\hline $\begin{array}{r}5 \% \\
\mathrm{H}_{2} \mathrm{SO}_{4}\end{array}$ & & & $\begin{array}{l}\text { Autoclaved } \\
\text { concrete }\end{array}$ \\
\hline $\begin{array}{c}5 \% \\
\mathrm{CH}_{3} \mathrm{COOH}\end{array}$ & & 7 & $\begin{array}{l}\text { Impregnated } \\
\text { autoclaved } \\
\text { concrete }\end{array}$ \\
\hline
\end{tabular}

Fig. 9. Weight changes of specimens after 28-dayimmersion in various reagents (Method $B$ ). 


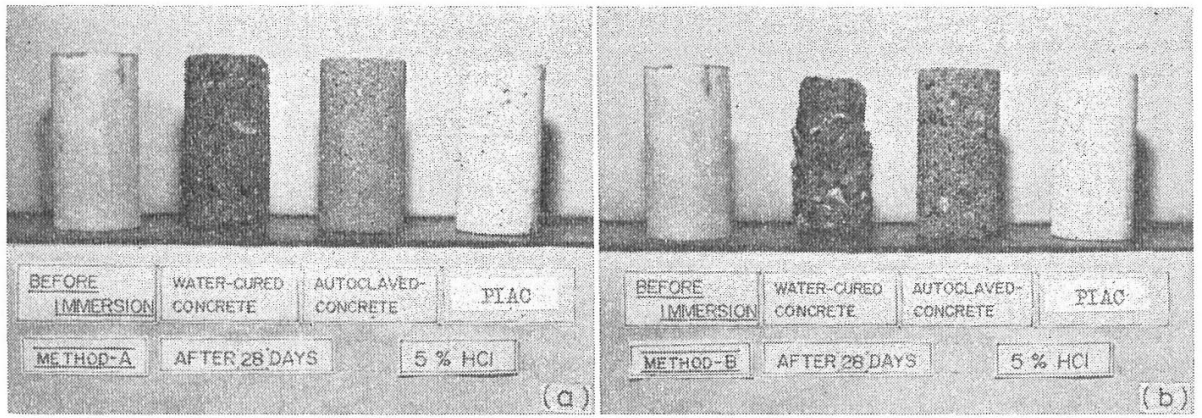

Fig. 10. Specimens after 28-day-immersion in 5\% $\mathrm{HCl}$.

も大きく変化し，AC 和よび WCC では浸食部分が白 色となり，骨材の露出が目立つものが多い、いずれに 呕よ， 3 種のコンクリートとも他の薬品に比べて, 酸 類に対する抵抗性は亦まりすぐれないようである。し かしながら，AC 怙よび PIAC の耐酸性は，WCC K 比較すると，明らかに差異がが每ることがわかる。ま た，有機酸である眽酸に比べ，無機酸で方る塩酸抢上 び硫酸の方が，各種コンクリートに対する浸食が激し い.

さらに, 試験方法 $\mathrm{A}$ 拈よび $\mathrm{B}$ 法堂比較すると, 一定 期間ごとに㴆食部分学以ぎ取る B 法の方が，A法より 大きな重量変化定す。

な执，A法による硫酸の愓合，WCC では始めから 著しい重量減少を生ずるのに対し， AC 拉よび PIAC の場合には，浸せき初期の 3 日，7 日に出いて，重量 增加が認妨孔，その後は減少する傾向にある。

ここで, 各種酸類による浸食機構走教党てみると, 塩酸特上び硫酸では，次式のごとく、コンクリート中 のケイ酸石灰和よびアルミン酸石灰が分解する.

$2 \mathrm{CaO} \cdot \mathrm{SiO}_{2}+4 \mathrm{HCl} \longrightarrow 2 \mathrm{CaCl}_{2}+\mathrm{Si}(\mathrm{OH})_{4}$

$3 \mathrm{CaO} \cdot \mathrm{Al}_{2} \mathrm{O}_{3}+6 \mathrm{HCl} \longrightarrow 3 \mathrm{CaCl}_{2}+2 \mathrm{Al}(\mathrm{OH})_{3}$

$2 \mathrm{CaO} \cdot \mathrm{SiO}_{2}+2 \mathrm{H}_{2} \mathrm{SO}_{4} \longrightarrow 2 \mathrm{CaSO}_{4}+\mathrm{Si}(\mathrm{OH})_{4}$

$4 \mathrm{CaO} \cdot \mathrm{Al}_{2} \mathrm{O}_{3}+3 \mathrm{H}_{2} \mathrm{SO}_{4} \longrightarrow 3 \mathrm{CaSO}_{4}+2 \mathrm{Al}(\mathrm{OH})_{3}$

とくに, 硫酸では, 水酸化カルシウムと次式の上う な反応が起り，

$\mathrm{Ca}(\mathrm{OH})_{2}+\mathrm{H}_{2} \mathrm{SO}_{4} \longrightarrow \mathrm{CaSO}_{4} \cdot 2 \mathrm{H}_{2} \mathrm{O}$

$4 \mathrm{CaO} \cdot \mathrm{Al}_{2} \mathrm{O}_{3} \cdot 19 \mathrm{H}_{2} \mathrm{O}+3\left(\mathrm{CaSO}_{4} \cdot 2 \mathrm{H}_{2} \mathrm{O}\right)+16 \mathrm{H}_{2} \mathrm{O}$

$\longrightarrow 3 \mathrm{CaO} \cdot \mathrm{Al}_{2} \mathrm{O}_{3} \cdot 3 \mathrm{CaSO}_{4} \cdot 31 \mathrm{H}_{2} \mathrm{O}+\mathrm{Ca}(\mathrm{OH})_{2}$

または，

$3 \mathrm{CaO} \cdot \mathrm{Al}_{2} \mathrm{O}_{3} \cdot 12 \mathrm{H}_{2} \mathrm{O}+3\left(\mathrm{CaSO}_{4} \cdot \mathrm{H}_{2} \mathrm{O}\right)+13 \mathrm{H}_{2} \mathrm{O}$

$\longrightarrow 3 \mathrm{CaO} \cdot \mathrm{Al}_{2} \mathrm{O}_{3} \cdot 3 \mathrm{CaSO}_{4} \cdot 31 \mathrm{H}_{2} \mathrm{O}$

水に難溶性の大きな針状結晶であるセメントバチルス 炎生成し, 約 2.5 倍の体積增加を就こして膨張する゙.

また, 酢酸の場合には, 水酸化カルシウムと次式のご とく区応して,

$\mathrm{Ca}(\mathrm{OH})_{2}+2 \mathrm{CH}_{3} \mathrm{COOH} \longrightarrow \mathrm{CH}_{3} \mathrm{COO}>\mathrm{Ca}+2 \mathrm{H}_{2} \mathrm{O}$

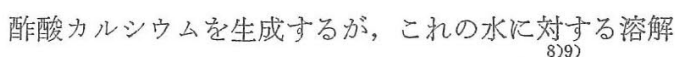
度は，水酸化カルシウムの色秃よりも大きいので，か なりの浸食が起ることになる。

一般に，AC 㧊よび WCC に比べて，PIAC の塩酸， 硫酸禾よび酢酸に対する抵抗性が著しく優れる原因は， コンクリート中の多くの空げきが，耐酸性に優れたポ

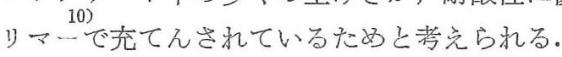

オートクレーブ養生コンクリートの塩酸招上び硫酸 に対する抵抗性については, 前述の杉木らのデーダが あるが，これと本実験の結果とは慓ぼ一致している。

\section{$5 \cdot 2$ アルカリ類（水酸化ナトリウム）に対する} 抵抗性

代表的なアルカリで要る水酸化ナトリウムに対する ニンクリートの抵抗性は，セヌント自体が $\mathrm{pH} 12$ 程 度の強アルカリであるため, ほとんど問題はないとさ 孔ている。

本実験では，水酸化ナトリウムに対する重量減少率 世，AC，WCC 怙上び PIAC のいずれにる極的て小 さく,から，三者ともほほ注等しい值である。

水酸化ナトリウム浸せき後28日目に蛙いて，WCC では表面がねばねばし，多少キズがつく軽微な浸食を 受ける、AC は WCC 滦どではないが，わずかな表面 変化が観察される。PIAC は表面す硬く, 外観上の変 化は卧とんど認められない。

\section{$5 \cdot 3$ 塩類に対する抵抗性}

試験した塩類薬液の中で, 食塩は各種のコンクリー トにほ上んど無害であるのに効し，硫酸塩の代表であ る硫酸アンモニウムは，一般にコンタリートに対し大 きな浸食作用を与克る。

硫酸アンモニウムへの浸地き期間が長くなるにつれ て, WCC の重量減少法多く, 著しい浸食を受けるの に対して, AC 敊よび PIAC の重量変化は極めて小さ く，相当の抵抗性学有することがわかる。

この理由を考爷てみると，WCC では次式のごとく， $\mathrm{Ca}(\mathrm{OH})_{2}+\left(\mathrm{NH}_{4}\right)_{2} \mathrm{SO}_{4} \longrightarrow \mathrm{CaSO}_{4} \cdot 2 \mathrm{H}_{2} \mathrm{O}+2 \mathrm{NH}_{3}$ 遊離した水酸化カルンウムと硫酸アンモニウムとの反 応で石こうを生じ，これと先に述べたせメントン゚チル 
スの生成反応が続いて起り, 硫酸の場合と同様, 大き な害作用を及ぼすのに対し，AC では，ち密な組織と 遊離の水酸化カルシウムをもっていないため，また， PIAC では, ら密な組織にさらに耐硫酸性のすぐれた ポリマーが充てんされているため, WCC の場合のよ らな有害な化学反応を生じにくくなっているものと考 えられる。

塩化ナトリウムは, 有害なセメントバチルス $(3 \mathrm{CaO}$ - $\left.\mathrm{Al}_{2} \mathrm{O}_{3} \cdot 3 \mathrm{CaSO}_{4} \cdot 31 \mathrm{H}_{2} \mathrm{O}\right)$ の水に対する溶解度を高 めるので, この結晶生成を妨げる効果があり, コンク リートにとっては無害であるとの報告がある.

本実験に拈いても，塩化ナトリウムは WCC, AC および PIAC のいずれをもほとんど浸食しない.

\section{$5 \cdot 4$ 油類に対する抵抗性}

ナタネ油は, 高級脂肪酸のグリセリドである.ナタ ネ油に最初から含まれる遊離の脂肪酸は, 更にコンク リートのアルカリと反応して, 脂肪酸カルシウムとな り，また，ケン化によって生じたグリセリンは水酸化 カルシウムを溶解するため，一般にナタネ油に対する コンクリートの抵抗性は不良となる. しかしながら， 本実験の結果からみると, ナタネ油の浸せき期間の増 加に対して, AC, PIACおよび WCC の重量変化率は, 極めて小さく, その抵抗性は, 優れているようである. な拉， AC と PIAC は外観変化がないのに比べ, WCC ではその表面に亀甲状のひび割れを生じる.

コンクリートは燈油扎よび重油とは全く反応せず, 浸食を受けないといわれる。

本実験結果についても同様で， 3 種類のコンクリー 卜とも浸せき28日後に拈いても, 外観上, 汪とんど変 化がみられない，重量変化率はいずれも極めて小さく て，燈油执よび重油に対する抵抗性は充分大きいこと がわかる.

\section{$5 \cdot 5$ ビールに対する抵抗性}

A. Moye によれば，ビールがコンクリートに及ぼす 影響は, 主として発酵の際に多量に発生する炭酸ガス によるものであって, その他, 乳酸, 酢酸, タンニン 酸などの酸類も発酵したビール中には，小量存在して 害をなすとしているが, 別の文献では, 生ビールはコ ンクリートを全く浸食しないといら報告もある.

本実験では，WCC のみ，生ビール浸せき28日後， $0.45 \%$ 重量減少があり, その表層部がやや軟化する. $\mathrm{AC}$ 抢よび PIAC はその表層部も硬く, かつ, ひび 割れなど，外観上の変化は全く見られない.

\section{6 結論}

オートクレーブ養生コンクリート (AC) 执よびポリ マー含浸オートクレーブュンクリート (PIAC) の耐薬 品性を標準養生による普通コンクリート (WCC) のそ れと比較すると, 本実験の結果からは, 次のことが要
約される.

(1) $\mathrm{AC}$ の塩酸, 硫酸, 酢酸のような無機および有 機酸類に対する抵抗性は必ずしも優れないようである が，WCC と比べれば，はるかに良好である。な稆， PIAC はいずれの酸類に対してもACより抵抗性は大 きいが，浸せき期間が長くなると，やはり浸食度合は 漸增する.

（2）アルカリ類の代表である水酸化ナトリウムに対 しては，AC および PIAC とも浸食作用は認められな い. WCC では，浸せき28日後にいたり，その表面に 水ばねばした物質が生じ, つめの痕跡が残る程度の極 めて軽微な浸食が見られる。ただし, 重量変化率は AC， PIAC 抢よび WCC ともほとんど等しく，浸せ き28日後に括いてー0.24\%である.

（3）塩化ナトリウムに対しては， AC， PIAC およ び WCC ともほとんど浸食されない，硫酸アンモニウ ムに対しては，AC はやや膨潤して表面組織が粗とな るが，PIAC では浸食はほとんど認められず，すぐれ た抵抗性を示す. AC および PIAC に比較して, WCC は硫酸アンモニウムによる著しい浸食を受け，表層部 の粗骨材が露出する.

(4) AC および PIACのナタネ油に対する抵抗性は, かなりすぐれている，WCC では重量変化率は極めて 小さいが，その表面に亀甲状のひび割れを生じる，燈 油和よび重油のような鉱物油については，AC, PIAC 抢よび WCC のいずれも浸食はほとんど認められない。

(5) 生ビールに対しては，AC 抢よび PIAC とも浸 食はほとんど認められない，WCC では表面の薄層部 がやや軟化し，軽微な浸食を受ける.

最後に, 本研究は昭和51年度日本大学工学部建築材 料研究室の卒業研究生犬石衛一君, 他 4 名の協力によ り行われたものであることを記し, 謝意を表する次第 である。

\section{参考文 献}

1）日本コンクリート工学協会編, “コンクリート便覧”, p. 887 (1976) 技報堂

2) Frederick, M. Lea, "The Chemistry of Cement and Concrete”, p. 294 (1956) Edward Arnold Ltd., London

3) Imre Biczók, "Concrete Corrosion and Concrete Protection”, p. 247 (1964) Akadémiai Kiadó, Budapest

4）大浜嘉彦，建築研究報告，No. 65, 205 (1973) 建設省 建築研究所

5) Frederick, M. Lea, "The Chemistry of Cement and Concrete", p. 345 (1970) Edward Arnold Ltd., London

6) Neville, A. M, "Properties of Concrete", p. 335 (1963) Pitman Publishing, London

7) Imre Biczók, "Concrete Corrosion and Concrete Protection”, p. 172 (1964) Akadémıai Kiadó, Budapest 
8) Fredrick, M. Lea, "The Chemistry of Cement and Concrete", p. 661 (1970) Edward Arnold Ltd., London

9) Imre Biczók, "Concrete Corrosion and Concrete Protection”, p. 252 (1964) Akadémiai Kradó, Budapest

10）須本一郎, “スチロール系樹脂”, p.115（1970）日刊工 業新聞社

11) Imre Biczók, "Concrete Corrosion and Concrete Protection”, p. 305 (1964) Akadémiai Kiadó, Budapest

12）Czernin, W. (德根吉郎訳), “建設技術者のためのセメ ントコンクリート化学”, p. 139 (1969) 技報堂

13) Imre Biczók, "Concrete Corrosion and Concrete Protection”, p. 175; p. 232 (1964) Akadémiai Kiadó, Budapest

14) Frederick, M. Lea, "The Chemistry of Cement and
Concrete”, p. 662 (1970) Edward Arnold Ltd., London

15) Frederick, M. Lea, "The Chemistry of Cement and Concrete", p. 660 (1970) Edward Arnold Ltd, London

16) Imre Biczók, "Concrete Corrosion and Concrete Protection”, p. 324 (1964) Akadémiai Kiadó, Budapest

17）大浜嘉彦, 建築研究報告, No.65, 212 (1973) 建設省建 築研究所

18）Kleinlogel，A. (浜田稔訳)，“コンクリート総覧”， p. 128 (1942) コロナ社

19) Frederick, M. Lea, "The Chemistry of Cement and Concrete”, p. 675 (1970) Edward Arnold Ltd., London

20) Imre Biczok, "Concrete Corrosion and Concrete Protection”, p. 265 (1964) Akadémiai Kiadó, Budapest 